\title{
LEVERAGING MATURITY ASSESSMENT TO CHOOSE THE RIGHT APPLICATIONS FOR SMART CITIES: TURKEY'S APPROACH
}

\author{
H. Bayraktar ${ }^{1}$, D. Y. Bayar ${ }^{1}$, B. Kara ${ }^{1}$, G. Bilgin ${ }^{1, *}$ \\ ${ }^{1}$ Ministry of Environment and Urbanization, Directorate General of Geographic Information Systems, 06530 Çankaya Ankara, \\ Turkey - (huseyin.bayraktar, dyildirim.bayar, bestami.kara, gokhan.bilgin)@csb.gov.tr
}

KEY WORDS: Smart Cities, Maturity Model, Maturity Assessment, Smart City Applications, Smart City Index

\begin{abstract}
:
Cities are facing numerous challenges because of the unprecedented growth of population all over the world. In this context, smart city stands out as a viable option to improve quality of life. Smart city, with its ability to transform the information into economic, social and environmental benefits, offers acquisitions in the fields of sustainable development, competitiveness and environmental sustainability. However, the cost of implementing and maintaining smart city applications on a large scale reveals the necessity to choose the right smart city application at the beginning of smart city transformation. In order to determine which smart city application should be used in smart city domain, the current situation and needs of the city should be analysed effectively. Maturity assessment can be used as a tool to understand the existing conditions of a city. In this study, Turkey's smart city approach will be addressed and Smart City Maturity Assessment Model of Turkey will be introduced with the preparation and implementation process. Consequently, the impact of the Smart City Maturity Assessment Model on selection of smart city applications will be discussed with the result of maturity assessment which is implemented on 4 cities of Turkey.
\end{abstract}

\section{INTRODUCTION}

Over the last decades, the urban population percentage is increasing unprecedentedly. $30 \%$ of the world's population was urban in 1950 and \%54 world's population was residing in urban areas in 2014 (United Nations, Department of Economic and Social Affairs, 2014). Global population is likely (95 per cent) to number between 8.5 and 8.6 billion in 2030, between 9.4 and 10.1 billion in 2050, and between 9.4 and 12.7 billion in 2100 (United Nations, Department of Economic and Social Affairs, 2019).

Urban growth is putting significant stress on city infrastructure as demand outpaces supply for water, energy, transportation, healthcare, education, and safety (Naphade et al., 2011). Therefore, "smart" solutions should be found out which means they are efficient and feasible for economic growth of the city and society as well (Kaur and Maheshwari, 2016).

The concept of "smart cities" has emerged recently as a very promising solution for providing advanced services to the citizens enabled by Information and Communication Technologies (ICT) (Tragos et al., 2014). Smart cities can provide a high quality of life for the citizens, promote economic growth, and protect the environment from degradation and make sustainable development possible as well.

Smart cities are data-driven. A smart city is just not a technology but also an infrastructure based network that collects information from different types of electrical sensors to manage resources effectively (Al-Ani et al., 2019). Urban data are collected, analysed, vitalized and used to realize smartness in urban domains (Yin et al., 2015). The rate of data produced by cities and their citizens accelerates day after day (Korachi and Bounabat and, 2018). Smart city big data are two modern and important concepts; therefore, many started integrating them to develop smart city applications that will help reach sustainability, better resilience, effective governance, enhanced quality of life, and intelligent management of smart city resources (Al Nuaimi et al., 2015).

However, the heterogeneity and dynamic nature of smart city devices and infrastructure, as well as their large scale deployment, make building smart city applications difficult (Giang et al., 2016). Therefore, needs of cities must be determined accurately in order to prevent waste of resources of municipalities and central governments, ensure implementing the right smart city applications in the right domain and plan the investments. In this context, maturity assessment can be used as a tool to understand the existing conditions of a city in the way of its smart city transformation.

This paper will, in Section 2, introduce Turkey's smart city definition based on National Smart City Strategy and Action Plan of Turkey to understand Turkey's smart city transformation better. The necessity and the impact of maturity assessment in smart cities will be discussed and maturity assessment approach of Turkey will be introduced. Besides, it will be demonstrated that how to use maturity assessment to choose smart city applications with the data of 4 measured cities of Turkey. Finally, Section 3 concludes the paper.

\section{SMART CITY MATURITY ASSESSMENT MODEL OF TURKEY}

\subsection{Understanding Smart City Vision of Turkey}

A smart city concept is needed in order to implement a smart city maturity assessment for the purpose of determining the

Corresponding author 
current condition of a city. However, the smart city concept has been defined in numerous ways. It is clear that there is not a consensus on the requirements or attributes that characterise the smartness that those cities strive to achieve (Sanchez-Corcuera et al., 2019). Therefore it is necessary to understand Turkey's smart city vision before examining the maturity assessment approach.

It is crucial to ensure the availability of reliable governance systems that plan, manage, and measure the transformation of being smart (Aljowder and Kurnia, 2019). With a similar motivation in Turkey, 2020-2023 National Smart Cities Strategy and Action Plan (NSAP) has been drawn up with the aim to gain the ability of interoperability by means of bringing a holistic perspective in smart city policies on a national level. With the NSAP, it will be ensured that the investments are utilized in the correct projects and activities by the competent and producing smart city ecosystem by means of prioritizing the investments that meet the requirements of the designated policies (Ministry of Environment and Urbanization, 2019).

Within the scope of NSAP, it is aimed to set a mutual vision and a road map, monitor and evaluate with a systematic and open governance process, accommodate new conditions and develop the smart city maturity with a common perspective in the cities.

The definition of smart city is one of the most basic tools that reveal the smart city vision of companies, cities or countries. Hence, in the preparatory studies of NSAP, describing the term "smart city" was the primary step. In this context, various studies regarding to smart city definitions was reviewed. (British Standard Institute, 2014) has given the definition of "smart cities" as "The Smart City is the effective integration of physical, digital and human systems into a structured environment to provide a sustainable, prosperous and inclusive future to Ecosystem assets." (The Department for Business, Innovation and Skills, 2013) defined a smart city as "The Smart Cities are defined as a process that makes cities more liveable, flexible and more responsive to challenges increasing citizenship participation rather than a static result, as well as improving the physical infrastructure, social capital and digital technologies." (European Parliament, 2014) defined a smart city as "Multi-stakeholder municipally based partnerships aimed at addressing problems of common interest with the aid of ICTs, which underpin 'Smart' classification." (International Telecommunication Union, 2016) defined a smart city as "The smart and sustainable city, while considering the economic, social, environmental and cultural needs of current and future generations on one side, it is also recognized as an innovative city that uses information and communication technologies and other tools to increase the quality of life, efficiency and competitiveness of city service provision."

The smart city concept has been defined in numerous different ways and consensus has not yet been reached. Within the scope of NSAP, the term "smart city" has been described as follows: "More liveable and sustainable cities that are brought into being with the inter-stakeholder collaboration, utilizing emerging technologies and innovative approaches, providing justification based on data and specialty, and producing solutions adding value to our lives by predicting the future problems and needs."

As a complex concept, the term smart city needs to be addressed structurally. Not only are there various definitions of this term, there are also various approaches within the scope of standard, maturity assessment model, index and architecture studies concerning the conceptual structure of smart city.

However, the smart city structure varies on different visions and goals. The components identified under the (International Telecommunication Union, 2016) are Information and Communication Technologies (ICT), Environmental Sustainability, Efficiency, Quality of Life, Equality and Social Inclusion and Physical Infrastructure. Within the scope of (Giffinger et al., 2007), six components have been identified: Smart Economy, Smart People, Smart Management, Smart Mobility, Smart Environment and Smart living.

The Smart City Structure has been addressed under two main topics within the scope of NSAP. First topic is "Smart City Management" and competencies of this topic are listed in Table 1 .

\begin{tabular}{ll}
\multicolumn{2}{c}{ Smart City Management } \\
\hline Governance & Integrated Service Management \\
\hline Strategy Management & Business Management \\
\hline
\end{tabular}

Policy Management

Table 1. Competencies of Smart City Management

Second topic is "Smart City Applications" and the competencies of those topics are listed in Table 2.

\section{Smart City Applications}

\begin{tabular}{ll} 
Smart Environment & Information Technologies \\
\hline Smart Security & Smart Transportation \\
\hline Smart Resident & Smart Energy \\
\hline Smart Building & Communication Technologies \\
\hline Smart Economy & Information Security \\
\hline Smart Space Management & Smart Infrastructure \\
\hline Smart Health & Smart Governance \\
\hline Geographic Information & $\begin{array}{l}\text { Natural Disaster and } \\
\text { Systems }\end{array}$ \\
\hline
\end{tabular}

Table 2. Competencies of Smart City Applications

2020-2023 National Smart Cities Strategy and Action Plan has been built on a multi-level structure, including national and local layer, in a manner covering the entire country's smart city transformation, by means of taking into account the needs created by different dynamics such as socioeconomic status and geographical structure.

In order to realize the smart city transformation, the policies that need to be handled in a holistic manner with a common approach and understanding on country scale are addressed in the national layer, and the policies shaped according to different city dynamics are addressed in the local layer (Ministry of Environment and Urbanization, 2019).

\subsection{Smart City Maturity Assessment Model}

Maturity model is a framework that describes the behaviours, practices, and processes to evaluate the capability of an organization (Firmanyah et al., 2017). Maturity models generally aims to make organizations to measure and optimize 
the progression of skills and competences developed in a particular area (Afonso et al., 2015).

Once it has decided on transformation, a city must evaluate its needs and innovation opportunities, set clear objectives, prioritize development efforts, and establish metrics that let city planners, ICT consultants, and residents assess progress (Naphade et al., 2011). Maturity models for smart cities have been defined to help city leaders assess the city's current state and provide guidance towards its evolution (Torrinha and Machado, 2017).

Within the scope of the NSAP, studies were carried out to provide a country-specific Smart City Maturity Assessment Model (SCMAM), which creates a common language and a systematic structure in order to guarantee the development of maturity of all cities together.

SCMAM was developed with the aim of determining the smart city maturity level by evaluating the smart city capabilities of a cities and providing suggestions for the improvement of the maturity level. Thus, it was aimed to contribute to the smart city transformations of the municipalities in a structural, standard, consistent, effective and efficient manner.

A city own benchmark is a primordial thing to define a private vision since own needs are different from one city to another, such as the needs and challenges, which consider the population density, topography and infrastructure as basics (Arroub et al., 2016). Cities in Turkey need specific suggestions to improve their smart city vision due to they are at different levels of smart city maturity. It will be ensured that these suggestions have a teaching and guiding structure that provides clear and defined results at achievable stages.

There are indices in the world that use maturity assessment models for smart cities, which allow to evaluate different cities together, independent of countries. (International Telecommunication Union, 2016), (UNECE, 2015), (Radecki, 2013), (Giffinger et al., 2007), (Montalto et al., 2017) could be seen as examples of these indices.

In this respect, SCMAM takes international examples into consideration. During the determination of the structure of SCMAM, ISO $37120^{1}$, PAS $181^{2}$, Morgenstadt Framework Model (Radecki, 2013) and ITU Smart and Sustainable Cities Creation Model (International Telecommunication Union, 2016) were exploited. Similar to the key action fields in the Morgenstadt Framework Model, the dimension of the Action Field was defined to represent the whole of the activities carried out regarding the smart city transformation. In addition to the dimension of the Action Field included in the model, State and Impact representation was adopted on performance indicators in order to reveal the current state of the city and the impact to be achieved as a result of the activities performed. In Morgenstadt Framework Model, an evaluation and demonstration is made by establishing relations with key areas of activity based on performance indicators. Pressure, State and Effect classes are used in the classification made for performance indicators. It is considered appropriate to add the State and Effect classes from the indicator classification structure in Morgenstadt, to the

${ }^{1}$ ISO 37120, https://www.iso.org/standard/62436.html

${ }^{2} \mathrm{PAS}$ 181, https://www.bsigroup.com/en-GB/smart-cities/Smart-CitiesStandards-and-Publication/PAS-181-smart-cities-framework/
SCMAM model. The main structure of SCMAM is demonstrated in Figure 1.

In the structure, "State" consists of indicators that determine the current state of the city, which concerns the smart city transformation. "Action Field" consists of actions related to the smart city transformation. "Impact" consists of indicators that determine the impact of smart city studies on the city.

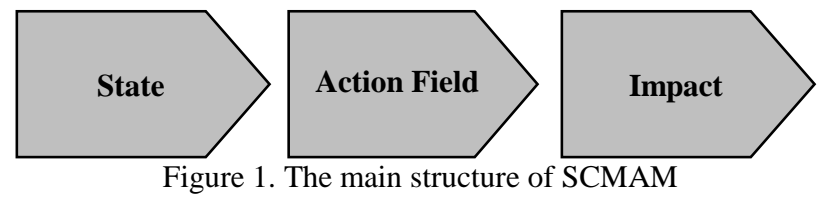

In the SCMAM, "components" and "capabilities" have been determined under the "competencies" as a structure in the dimension of the Action Field. Capabilities are the skills that cities need/will need, or acquire/will acquire with smart city studies, in order to perform smart city studies for a specific purpose. Component is a group of capabilities that serve the same value. Competency, on the other hand, is a group of components based on sectoral, expertise or service areas. In the smart city domain, each competency is a whole and can be handled individually in evaluations.

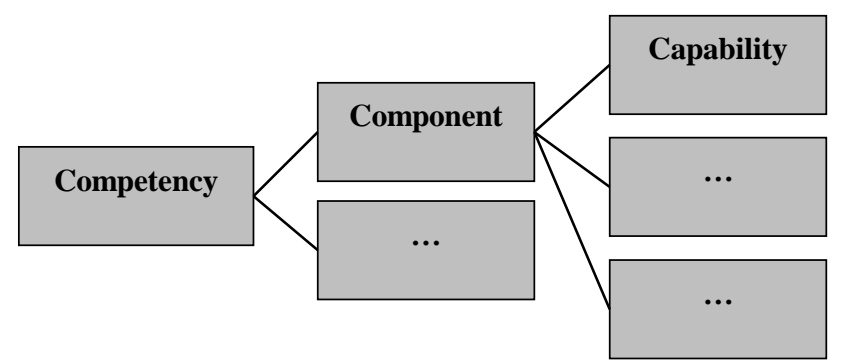

Figure 2. Action Fields Structure of SCMAM

One of the two scopes seen in maturity model reviews is the governance of the smart city, and the other is smart city applications. While some of these models focus on one of this scope, there are also some works focusing on the both. While ISO 37120 focuses on governance, the (International Telecommunication Union, 2016) focuses on applications, while Morgenstadt focuses on both governance and application. Within the scope of SCMAM, governance perspective is included in the model in order to ensure the reflection of the national strategy at the local level, the smart city applications section is also included in the model in order to raise awareness about smart city solutions within the maturity assessment studies in the local level.

One of the main issues in developing maturity model is to choose components (Firmansyah et al., 2017). The competencies, components and abilities to be used for maturity assessment in the smart city domain are defined in Table 1 and Table 2 .

In the SCMAM, question-answer method was adopted over a question set that is used in interviews, carried out online for maturity assessment. Questions are generated from tangible assets to be answered as $0-1$. Collected data from surveyed cities are then analysed and calculated to produce a value regarding to maturity of the city. 
In this study, the smart city maturity assessment process and results for 4 cities will be explained and shared, but the names of the cities will not be referred, they will be represented by letters, as assessment studies have not been completed on the country scale yet. After the maturity assessment studies are completed across the country, smart cities index will be created and shared in future studies.

For the municipalities, where the level of smart city maturity will be assessed, preliminary information was collected and smart city ecosystem stakeholders were identified. Afterwards, questions determined for each ability were asked online. Besides, relevant information, documents or physical evidence were requested from stakeholders. The data obtained by using various data collection methods such as the information obtained in the assessment interview, the data gathered from documents, the results of the survey evaluated, direct observation, participant observation and physical findings were consolidated, and the answers of the questions grouped under the capability maturity level to reach a common conclusion. While calculating the smart city maturity level of the city, the average of the answers of the questions was obtained under each capability. Component and competency maturity levels were determined based on the capability maturity levels. The maturity level of the city has been determined by taking into account the competency maturity levels.

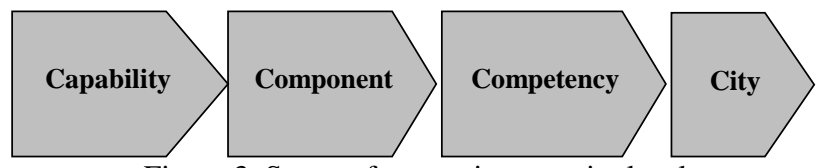

Figure 3. Scope of smart city maturity level

The four cities which are selected for this study have different scales and they are located in different regions of Turkey. City $\mathrm{A}$ is a provincial municipality while $\mathrm{B}, \mathrm{C}, \mathrm{D}$ are metropolitan municipalities. Population of cities ranges from 500.000 to 1.000.000.

In the assessment process, the same procedure was followed for all abilities, components and competencies. Therefore, the studies carried in maturity assessment will be explained within the context of smart city applications competency, and "smart environment" is chosen as component which is one of the most used applications in smart cities domain.

\begin{tabular}{|c|c|}
\hline Component & Capability \\
\hline \multirow{8}{*}{ Smart Environment } & Water Management \\
\hline & Waste Management \\
\hline & Green City \\
\hline & Clean Air \\
\hline & Clean Environment \\
\hline & Combating Climate Change \\
\hline & Soil Management \\
\hline & Environment Management \\
\hline \multicolumn{2}{|c|}{ Table 3. Structure of "Smart Environment" component } \\
\hline
\end{tabular}

It can be seen in the sample questions, the basic question logic is built on concrete assets. The answers can be "yes/no" or "implemented/not implemented", and must be supported with complementary documents or explanations as aforementioned.

\begin{tabular}{ll}
\hline Question & Capability \\
\hline $\begin{array}{l}\text { Is there a smart city solution used within } \\
\text { the scope of drinking water quality? }\end{array}$ & Water Management \\
\hline $\begin{array}{l}\text { Is there an automatic meteorological } \\
\text { observation station? }\end{array}$ & Clean Air \\
\hline $\begin{array}{l}\text { Is there a smart city solution used within } \\
\text { the waste recycling? }\end{array}$ & $\begin{array}{l}\text { Waste } \\
\text { Management }\end{array}$ \\
\hline $\begin{array}{l}\text { Is there a smart city solution used for } \\
\text { reducing greenhouse gas emission? }\end{array}$ & $\begin{array}{l}\text { Combating Climate } \\
\text { Change }\end{array}$ \\
\hline
\end{tabular}

Table 4. Sample questions about "Smart Environment"

The answers are grouped by abilities and average of the values corresponds the maturity level of related capability. Likewise, maturity level of the component consists of average value gathered from maturity level of abilities. Maturity level of City A, regarding to "Smart Environment" component is shown in the Figure 4 with the related abilities.

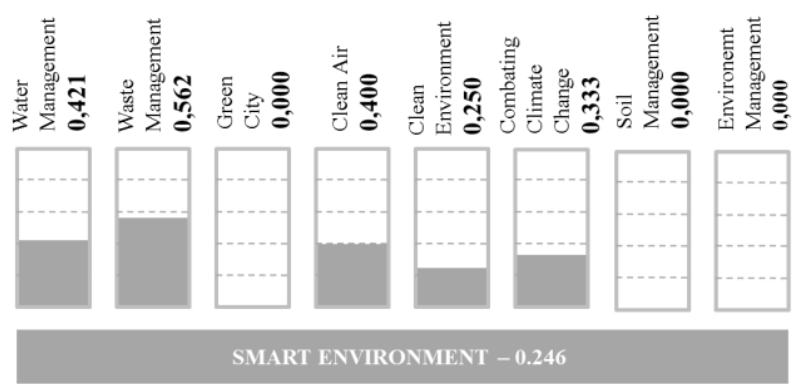

Figure 4. Smart environment maturity level of City A

"Smart Environment" component is a part of "Smart City Applications" competency, with the other 15 components shown in the Table 2. As it can be seen in Figure 4, the maturity level of "Smart Environment" component is calculated as " 0.246 ". The value is generated from the average of the abilities as mentioned before.

However, it is important to emphasize that answers gathered from interviews are not the only element of the maturity levels. Although the existence of smart city applications is a criterion, the scale of the applications and their impact on the city are also important factors to be evaluated. For this reason, explanations, project documents related to the applications and other documents that can be considered as evidence were collected in maturity assessment interviews, the answers were evaluated and final values are modified with the complementary knowledge.

In this context, same methods implemented to assess the maturity levels of 4 cities. Maturity assessment interviews were conducted with questions similar to those in Table 4. As the scope, the flow is followed that is shown in Figure 3. Results are listed in Table 5.

As can be seen clearly from Table 5 , the maturity levels of cities may differ significantly on the basis of components and it is obvious that regardless of the city's population, the domains where cities invest in smart cities vary. 


\begin{tabular}{|c|c|c|c|c|}
\hline & $\mathbf{A}$ & B & C & D \\
\hline Smart City Applications & $\mathbf{0 . 3 3}$ & 0.25 & 0.40 & 0.29 \\
\hline Smart Environment & 0.25 & 0.28 & 0.29 & 0.16 \\
\hline Smart Security & 0.07 & 0.29 & 0.25 & 0.21 \\
\hline Smart Resident & 0.42 & 0.57 & 0.68 & 0.37 \\
\hline Smart Building & 0.12 & 0.09 & 0.42 & 0.09 \\
\hline Smart Economy & 0.17 & 0.01 & 0.09 & 0.09 \\
\hline Smart Spatial Management & 0.47 & 0.46 & 0.52 & 0.25 \\
\hline Smart Health & 0.06 & 0.00 & 0.00 & 0.00 \\
\hline $\begin{array}{l}\text { Geographic Information } \\
\text { Systems }\end{array}$ & 0.44 & 0.89 & 0.47 & 1.00 \\
\hline Information Technologies & 0.07 & 0.06 & 0.23 & 0.04 \\
\hline Smart Transportation & 0.74 & 0.40 & 0.37 & 0.24 \\
\hline Smart Energy & 0.44 & 0.21 & 0.51 & 0.00 \\
\hline Communication Technologies & 0.60 & 0.00 & 0.73 & 0.45 \\
\hline Information Security & 0.23 & 0.04 & 0.62 & 0.31 \\
\hline Smart Infrastructure & 0.00 & 0.00 & 0.14 & 0.50 \\
\hline Smart Governance & 0.65 & 0.36 & 0.76 & 0.64 \\
\hline $\begin{array}{l}\text { Natural Disaster and } \\
\text { Emergency Management }\end{array}$ & 0.52 & 0.40 & 0.37 & 0.35 \\
\hline Smart City Management & 0.68 & 0.00 & 0.30 & 0.39 \\
\hline Governance & 0.87 & 0.00 & 0.33 & 0.25 \\
\hline Strategy Management & 0.50 & 0.00 & 0.00 & 0.33 \\
\hline Policy Management & 0.67 & 0.00 & 0.33 & 0.30 \\
\hline $\begin{array}{l}\text { Intagrated Service } \\
\text { Management }\end{array}$ & 0.82 & 0.00 & 0.65 & 0.85 \\
\hline Business Management & 0.53 & 0.00 & 0.21 & 0.22 \\
\hline Maturity Level of City & 0.50 & 0.13 & 0.35 & 0.34 \\
\hline
\end{tabular}

Table 5. Maturity assessment results of 4 cities

For the "Smart Transportation" component, City A is far ahead of the rest but there is no smart city application regarding to "Smart Infrastructure" in City A. Similar outcomes can be derived from the results. In the future works for City D, there is no need to invest in "Geographic Information Systems" component to avoid waste of resources, so funds can be used for other application areas, "Information Technologies" for instance, since the maturity level of the component is significantly low. It is even possible to make a deeper analyse on capability level that each component consists of capabilities as underlined before.

Maturity assessment model is a great tool for city administrator to take a snapshot of their city. Information gathered from maturity assessment can be utilized to propose a development roadmap and recommendations and to determine the right application in the right domain to implement for the measured city.

\section{CONCLUSIONS}

Smart solutions are used in cities to improve quality of life of the society. In order to choose the right application to be implemented, it is necessary to reveal the current situation, deficiencies and strengths of the cities clearly.

SCMAM was developed with the aim of determining the smart city maturity level by evaluating the smart city capabilities of cities and providing suggestions for the improvement of the maturity level. The model will contribute to the smart city transformations of cities in a structural, standard, consistent, effective and efficient manner. Smart city maturity assessment enables cities to prepare programs for investment on applications, projects and services by prioritizing the needs of the cities in order to improve the current level. Waste of resource and time can be avoided by ensuring the implementation of the right application in the right area.

As a result of the maturity assessment of cities with SCMAM, it has been observed that cities have different maturity levels in different smart city domains and these differences are population agnostic. Therefore, in order to improve the vision and maturity of cities, it is essential to provide city-specific recommendations in certain smart city domains where the shortcomings of cities are identified with maturity assessment. Besides, with the measurement studies that are repeated at regular intervals, improvements will be made visible for all authorities, including non-governmental organizations and citizens. In addition maturity model can be used to create a smart city index on country scale and monitor reflection of national smart city strategy on local.

The model has been created with the knowledge and experience currently available. As the number of implementations of the model increases, institutional memory will develop and the depth of knowledge related to implementation will improve. An assessment can be added to prioritize the solution suggestions by determining the criticality level of these suggestions.

This study offers a reference to researchers, institutions and governments regarding to smart city maturity model and how to use it to choose smart city applications in an efficient way as detailed information is presented about the preparation process of Smart City Maturity Assessment Model and its implementation at national level.

\section{REFERENCES}

Afonso, R., Dos, K., Brito, S., Nascimento, C., Garcia, V., Alvaro, A., 2015. Brazilian Smart Cities: Using a Maturity Model to Measure and Compare Inequality in Cities. https://doi.org/10.1145/2757401.2757426

Al Nuaimi, E., Al Neyadi, H., Mohamed, N., Al-Jaroodi, J., 2015. Applications of big data to smart cities. J. Internet Serv. Appl. 6, 25. https://doi.org/10.1186/s13174-015-0041-5

Al-Ani, K., Abdalkafor, A., Nassar, A., 2019. Smart City Applications: A Survey. https://doi.org/10.1145/3361570.3361616

Aljowder, T., Kurnia, S., 2019. Systematic literature review of the smart city maturity model. https://doi.org/10.1109/3ICT.2019.8910321

Arroub, A., Zahi, B., Sabir, E., Sadik, M., 2016. A literature review on Smart Cities: Paradigms, opportunities and open problems. https://doi.org/10.1109/WINCOM.2016.7777211 
British Standard Institute, 2014. PAS 180:2014 Smart cities Vocabulary.

European Parliament, 2014. Mapping Smart Cities in the EU.

Firmansyah, H., Supangkat, S., Arman, A., Ariani, Y., 2017. Identifying component for building smart city maturity model through document based weighting and city problem in Indonesia. https://doi.org/10.1109/ICEEI.2017.8312464

Firmanyah, H.S., Supangkat, S.H., Arman, A.A., Adhitya, R., 2017. Searching smart city in Indonesia through maturity model analysis: (Case study in 10 cities), in: 2017 International Conference on ICT For Smart Society (ICISS). pp. 1-6. https://doi.org/10.1109/ICTSS.2017.8288880

Giang, N., Lea, R., Blackstock, M., 2016. On Building Smart City IoT Applications: a Coordination-based Perspective. https://doi.org/10.1145/3009912.3009919

Giffinger, R., Fertner, C., Kramar, H., Kalasek, R., Milanović, N., Meijers, E., 2007. Smart cities - Ranking of European medium-sized cities.

International Telecommunication Union, 2016. Shaping smarter and more sustainable cities: striving for sustainable development goals.

Kaur, M., Maheshwari, P., 2016. Building smart cities applications using IoT and cloud-based architectures. https://doi.org/10.1109/ICCSII.2016.7462433

Korachi, Z., Bounabat, B., 2018. Data Driven Maturity Model for Assessing Smart Cities, in: Proceedings of the 2nd International Conference on Smart Digital Environment, ICSDE'18. Association for Computing Machinery, New York, NY, USA, pp. 140-147. https://doi.org/10.1145/3289100.3289123

Ministry of Environment and Urbanization, 2019. 2020-2023 National Smart Cities Strategy and Action Plan.

Montalto, V., Moura, C., Langedijk, S., Saisana, M., 2017. The Cultural and Creative Cities Monitor - 2017 Edition. https://doi.org/10.2760/58643

Naphade, M., Banavar, G., Harrison, C., Paraszczak, J., Morris, R., 2011. Smarter Cities and Their Innovation Challenges. IEEE Comput. 44, 32-39. https://doi.org/10.1109/MC.2011.187

Radecki, A., 2013. The Morgenstadt Framework.

Sanchez-Corcuera, R., Núñez-Marcos, A., Sesma-Solance, J., Bilbao, A., Mulero Martínez, R., Zulaika, U., Azkune, G., Almeida, A., 2019. Smart cities survey: Technologies, application domains and challenges for the cities of the future. Int. J. Distrib. Sens. Netw. 15, 155014771985398. https://doi.org/10.1177/1550147719853984

The Department for Business, Innovation and Skills, 2013. Smart Cities Background Paper.

Torrinha, P., Machado, R., 2017. Assessment of maturity models for smart cities supported by maturity model design principles. https://doi.org/10.1109/ICSGSC.2017.8038586
Tragos, E.Z., Angelakis, V., Fragkiadakis, A., Gundlegard, D., Nechifor, C., Oikonomou, G., Pöhls, H.C., Gavras, A., 2014. Enabling reliable and secure IoT-based smart city applications, in: 2014 IEEE International Conference on Pervasive Computing and Communication Workshops (PERCOM WORKSHOPS). pp. 111-116. https://doi.org/10.1109/PerComW.2014.6815175

UNECE, 2015. UNECE/ITU Smart Sustainable Cities Indicators.

United Nations, Department of Economic and Social Affairs, 2019. World Population Prospects 2019.

United Nations, Department of Economic and Social Affairs, 2014. World urbanization prospects: the 2014 revision.

Yin, C., Xiong, Z., Chen, H., Wang, J., Cooper, D., David, B., 2015. A literature survey on smart cities. Sci. China Inf. Sci. 58. https://doi.org/10.1007/s11432-015-5397-4 